\title{
Product Cordial Graph in the Context of Some Graph Operations on Gear Graph
}

\author{
Udayan M. Prajapati' ${ }^{1}$ Karishma K. Raval ${ }^{2}$ \\ ${ }^{1}$ St. Xavier's College, Ahmedabad, India \\ ${ }^{2}$ Ahmedabad Institute of Technology, Ahmedabad, India \\ Email:udayan64@yahoo.com,karishma.raval13@gmail.com
}

How to cite this paper: Prajapati, U.M. and Raval, K.K. (2016) Product Cordial Graph in the Context of Some Graph Operations on Gear Graph. Open Journal of Discrete Mathematics, 6, 259-267.

http://dx.doi.org/10.4236/ojdm.2016.64022

Received: June 8, 2016

Accepted: September 6, 2016

Published: September 9, 2016

Copyright (c) 2016 by authors and Scientific Research Publishing Inc. This work is licensed under the Creative Commons Attribution International License (CC BY 4.0).

http://creativecommons.org/licenses/by/4.0/

\begin{abstract}
A graph $G=(V(G), E(G))$ is said to be a product cordial graph if there exists a function $f: V(G) \rightarrow\{0,1\}$ with each edge $u v$ assign the label $f(u) f(v)$, such that the number of vertices with label 0 and the number of vertices with label 1 differ atmost by 1 , and the number of edges with label 0 and the number of edges with label 1 differ by atmost 1 . We discuss the product cordial labeling of the graphs obtained by duplication of some graph elements of gear graph. Also, we derive some product cordial graphs obtained by vertex switching operation on gear graph.
\end{abstract}

\section{Keywords}

Product Cordial Labeling, Gear Graph, Duplication, Vertex Switching

\section{(c) (i) Open Access}

\section{Introduction}

We begin a simple, finite, undirected graph $G=(V(G), E(G))$, where $V(G)$ and $E(G)$ are vertex set and edge set respectively. For all other terminology, we follow Gross [1]. Now, we provide a brief summary of definitions and other information which are necessary for the present investigations.

Definition 1. If the vertices or edges or both of the graph are assigned values subject to certain conditions then it is known as vertex, edge, total labeling respectively.

For latest survey on graph labeling, we refer to Gallian [2]. Vast amount of literature is available on different types of graph labeling and more than 1000 papers have been published.

Definition 2. A mapping $f: V(G) \rightarrow\{0,1\}$ is called binary vertex labeling of $G$ and $f(v)$ is called the label of the vertex $v$ of $G$ under $f$. 
Definition 3. Given $f: V(G) \rightarrow\{0,1\}$ for each edge uv assign the label $|f(u)-f(v)|$. Then, $f$ is said to be a cordial labeling of $G$ if the number of vertices with label 0 and the number of vertices with label 1 differ atmost by 1 , and the number of edges with label 0 and the number of edges with label 1 differ by atmost 1.

Definition 4. A product cordial labeling of graph $G$ with vertex set $V$ is a function $f: V \rightarrow\{0,1\}$ such that each edge uv is assigned the label $f(u) f(v)$, the number of vertices with label 0 and the number of vertices with label 1 differ by atmost 1 and the number of edge with label 0 and the number of edge with label 1 differ by atmost 1 . A graph which admits a product cordial labeling is called a product cordial graph.

The notion product cordial labeling was introduced by Sundaram, Ponraj and Somasundaram [3]. They proved that following graphs are product cordial graph: tree, unicyclic graph of odd order, triangular snakes, dragons and helms. Vaidya and Barasara [4] also proved few results on product cordial graph. They showed that following graphs are product cordial: gear graph obtained from wheel graph $W_{n}$ if and only if $n$ is odd, web graph, flower graph and closed helm.

Definition 5. The neighborhood of a vertex $v$ of a graph is the set of all vertices adjacent to $v$. It is denoted by $N(v)$.

Definition 6. Duplication of a vertex of the graph $G$ is the graph $G^{\prime}$ obtained from $G$ by adding a new vertex $v^{\prime}$ to $G$ such that $N\left(v^{\prime}\right)=N(v)$.

Definition 7. Duplication of a vertex $v_{k}$ by a new edge $e=v_{k}^{\prime} v_{k}^{\prime \prime}$ in a graph $G$ produces a new graph $G^{\prime}$ such that $N\left(v_{k}^{\prime}\right)=\left\{v_{k}, v_{k}^{\prime \prime}\right\}$ and $N\left(v_{k}^{\prime \prime}\right)=\left\{v_{k}, v_{k}^{\prime}\right\}$.

Definition 8. Duplication of an edge $e=u v$ by a new vertex $w$ in a graph $G$ produces a new graph $G^{\prime}$ such that $N(w)=\{u, v\}$.

The notions of duplication of a vertex by a new edge and duplication of an edge by a new vertex were introduced by Vaidya and Barasara [5].

Definition 9. For a graph $G$ and a vertex $v$ of $G$, define a vertex switching $G_{v}$ as the graph obtained from $G$ by removing all edges incident to $v$ and adding edges joining $v$ to every vertex not adjacent to $v$ in $G$.

The notion vertex switching was introduced by Vaidya, Srivastav, Kaneria, and Kanani [6].

Definition 10. The graph $W_{n}=C_{n}+K_{1}$ is called wheel graph and the vertex corresponding to $K_{1}$ is called an apex vertex and vertices corresponding to $C_{n}$ are called rim vertices.

Definition 11. A gear graph is obtained from the wheel graph $W_{n}$ by adding a vertex between every pair of adjacent vertices of the n-cycle.

\section{Main Results}

Theorem 1. The graph obtained by duplication of each vertex of degree two in the gear graph is not a product cordial graph.

Proof. Let $W_{n}$ be the wheel graph with the apex vertex $v_{0}$ and consecutive rim vertices $v_{1}, v_{2}, v_{3}, \cdots, v_{n}$. To obtain the gear graph $G_{n}$ subdivide each of the rim edges $v_{1} v_{2}, v_{2} v_{3}, \cdots, v_{n-1} v_{n}, v_{n} v_{1}$ of the wheel graph by the vertices $u_{1}, u_{2}, \cdots, u_{n}$ respectively. 
Obviously $\left|V\left(G_{n}\right)\right|=2 n+1$ and $\left|E\left(G_{n}\right)\right|=3 n$. Let $G$ be the graph obtained from $G_{n}$ by duplicating each vertex $u_{i}$ of degree two by a vertex $u_{i}^{\prime}$ respectively for $i=1,2,3, \cdots, n$. Thus $|V(G)|=3 n+1$ and $|E(G)|=5 n$.

Case 1: $n$ is odd. Label the first $\frac{3 n+1}{2}$ vertices of the sequence $v_{1}, u_{1}, u_{1}^{\prime}, v_{2}, u_{2}, u_{2}^{\prime}, v_{3}, u_{3}, u_{3}^{\prime}, \cdots, v_{n-1}, u_{n-1}, u_{n-1}^{\prime}, v_{n}, u_{n}, u_{n}^{\prime}, v_{0}$ each with label 0 and the remaining vertices with label 1 .

Hence, we get $e_{f}(0)=\frac{5 n+7}{2}$ and $e_{f}(1)=\frac{5 n-7}{2}$. Thus $\left|e_{f}(0)-e_{f}(1)\right|=7>1$.

Thus, it does not admit product cordial labeling.

Case 2: $n$ is even. Label the first $\left\lfloor\frac{3 n+1}{2}\right\rfloor$ vertices of the sequence $v_{1}, u_{1}, u_{1}^{\prime}, v_{2}, u_{2}, u_{2}^{\prime}, v_{3}, u_{3}, u_{3}^{\prime}, \cdots, v_{n-1}, u_{n-1}, u_{n-1}^{\prime}, v_{n}, u_{n}, u_{n}^{\prime}, v_{0}$ each with label 0 and remaining vertices with label 1 .

Hence, we get $e_{f}(0)=\frac{5 n+4}{2}$ and $e_{f}(1)=\frac{5 n-4}{2}$. Thus $\left|e_{f}(0)-e_{f}(1)\right|=4>1$.

Select two vertices $a$ and $b$ from the sequence $u_{1}, u_{1}^{\prime}, v_{2}, u_{2}, u_{2}^{\prime}, v_{3}, u_{3}, u_{3}^{\prime}, \cdots, v_{n-1}$, $u_{n-1}, u_{n-1}^{\prime}, v_{n}, u_{n}, u_{n}^{\prime}, v_{0}$ having label 0 and 1 respectively. If we interchange the label of $a$ and $b$ than $e_{f}(0)$ increases and consequently $e_{f}(1)$ decreases. Thus $\left|e_{f}(0)-e_{f}(1)\right|>1$.

Let $A$ and $B$ be the set of all vertices with label 0 and 1 respectively. If we interchange the labels of $k$ many vertices from set $A$ to $k$ many vertices of set $B$ then $e_{f}(0)$ increases and consecently $e_{f}(1)$ decreases.

So the graph $G$ does not admit product cordial labeling. Hence, $G$ is not a product cordial graph.

Theorem 2. The graph obtained by duplication of each vertex of degree two by an edge in the gear graph is a product cordial graph.

Proof. Let $W_{n}$ be the wheel graph with the apex vertex $v_{0}$ and consecutive rim vertices $v_{1}, v_{2}, v_{3}, \cdots, v_{n}$. To obtain the gear graph $G_{n}$ subdivide each of the rim edges $v_{1} v_{2}, v_{2} v_{3}, \cdots, v_{n-1} v_{n}, v_{n} v_{1}$ of the wheel graph by the vertices $u_{1}, u_{2}, \cdots, u_{n}$ respectively. Obviously $\left|V\left(G_{n}\right)\right|=2 n+1$ and $\left|E\left(G_{n}\right)\right|=3 n$. Let $G$ be the graph obtained from $G_{n}$ by duplicating each vertex $u_{i}$ of degree two by an edge $u_{i}^{\prime} u_{i}^{\prime \prime}$ respectively for all $i=1,2,3, \cdots, n$. Thus $|V(G)|=4 n+1$ and $|E(G)|=6 n$.

Define a function $f: V(G) \rightarrow\{0,1\}$ as follows:

$$
f(x)=\left\{\begin{array}{l}
1, \text { if } x=v_{i}, i=0,1,2, \cdots, n ; \\
1, \text { if } x=u_{i}, i=1,2, \cdots, n \\
0, \text { if } x=u^{\prime}, i=1,2, \cdots, n \\
0, \text { if } x=u_{i}^{\prime \prime}, i=1,2, \cdots, n .
\end{array}\right.
$$

Thus $v_{f}(0)=2 n, v_{f}(1)=2 n+1, e_{f}(0)=3 n$ and $e_{f}(1)=3 n$. Clearly $\left|v_{f}(0)-v_{f}(1)\right| \leq 1$ and $\left|e_{f}(0)-e_{f}(1)\right| \leq 1$. Thus, $G$ admits product cordial labeling. Hence $G$ is a product cordial graph.

Illustration 1. The product cordial labeling of the graph obtained by duplication of each vertex of degree two by an edge in gear graph $G_{n}$ for $n=6$ and $n=7$ are 
shown in Figure 1.
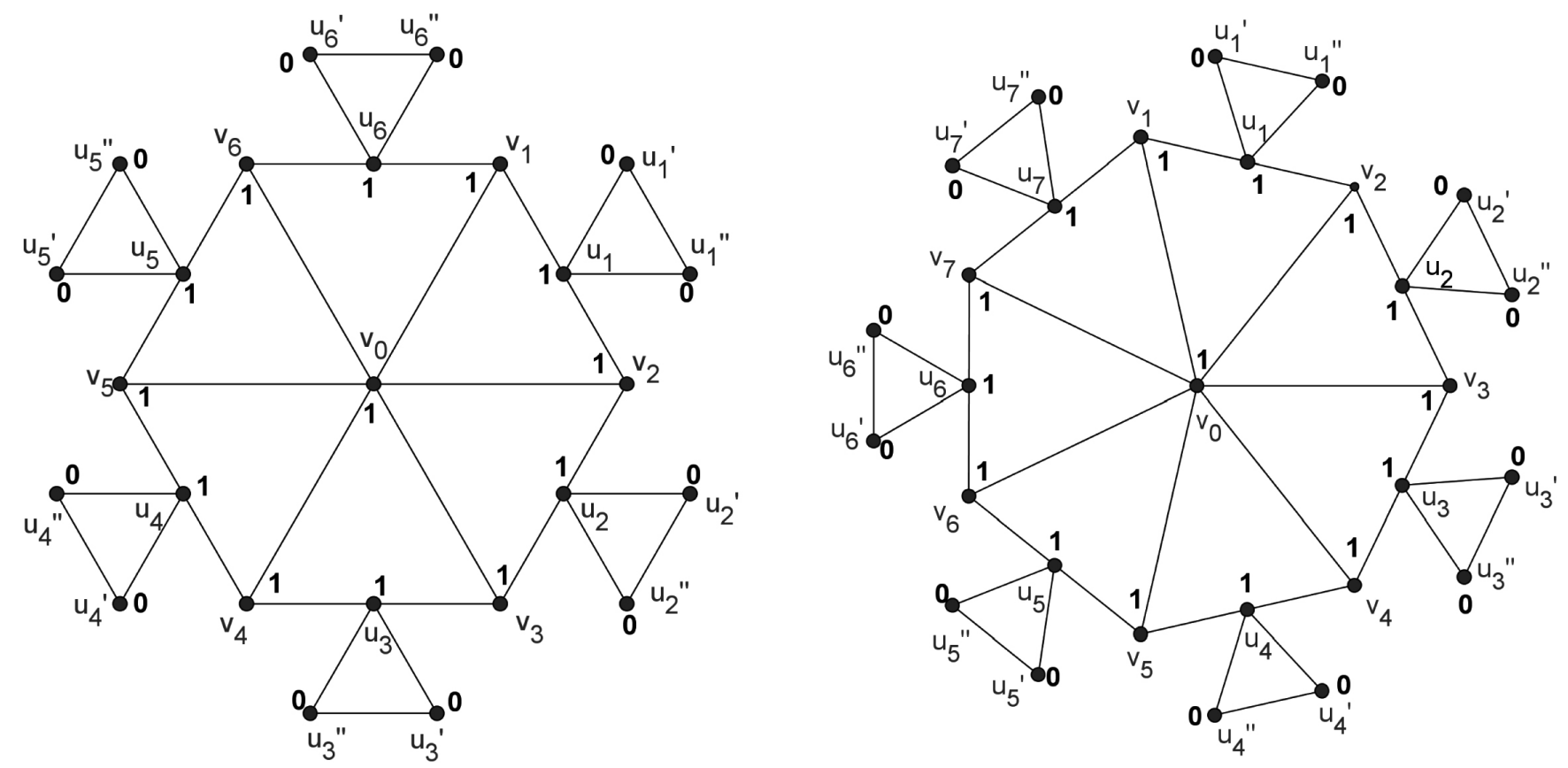

Figure 1. For $n=6$ and $n=7$.

Theorem 3. The graph obtained by duplication of each vertex of degree three by an edge in the gear graph is a product cordial graph.

Proof. Let $W_{n}$ be the wheel graph with the apex vertex $v_{0}$ and consecutive rim vertices $v_{1}, v_{2}, v_{3}, \cdots, v_{n}$. To obtain the gear graph $G_{n}$ subdivide each of the rim edges $v_{1} v_{2}, v_{2} v_{3}, \cdots, v_{n-1} v_{n}, v_{n} v_{1}$ of the wheel graph by the vertices $u_{1}, u_{2}, \cdots, u_{n}$ respectively. Obviously $\left|V\left(G_{n}\right)\right|=2 n+1$ and $\left|E\left(G_{n}\right)\right|=3 n$. Let $G$ be the graph obtained from $G_{n}$ by duplicating each vertex $v_{i}$ of degree three by an edge $v_{i}^{\prime} v_{i}^{\prime \prime}$ respectively for all $i=1,2,3, \cdots, n$. Thus $|V(G)|=4 n+1$ and $|E(G)|=6 n$.

Define a function $f: V(G) \rightarrow\{0,1\}$ as follows,

$$
f(x)=\left\{\begin{array}{l}
1, \text { if } x=v_{i}, i=0,1,2, \cdots, n ; \\
1, \text { if } x=u_{i}, i=1,2, \cdots, n \\
0, \text { if } x=v_{i}^{\prime}, i=1,2, \cdots, n \\
0, \text { if } x=v_{i}^{\prime \prime}, i=1,2, \cdots, n .
\end{array}\right.
$$

Thus, $v_{f}(0)=2 n, v_{f}(1)=2 n+1, e_{f}(0)=3 n$ and $e_{f}(1)=3 n$.

Clearly $\left|v_{f}(0)-v_{f}(1)\right| \leq 1$ and $\left|e_{f}(0)-e_{f}(1)\right| \leq 1$. So $G$ admits product cordial labeling. Hence, $G$ is a product cordial graph.

Illustration 2. The product cordial labeling of the graph obtained by duplication of each vertex of degree three by an edge in gear graph $G_{n}$ for $n=4$ and $n=5$ is shown in Figure 2.

Theorem 4. The graph obtained by duplication of the apex vertex in the gear graph by an edge admits product cordial labeling if $n$ is even. 

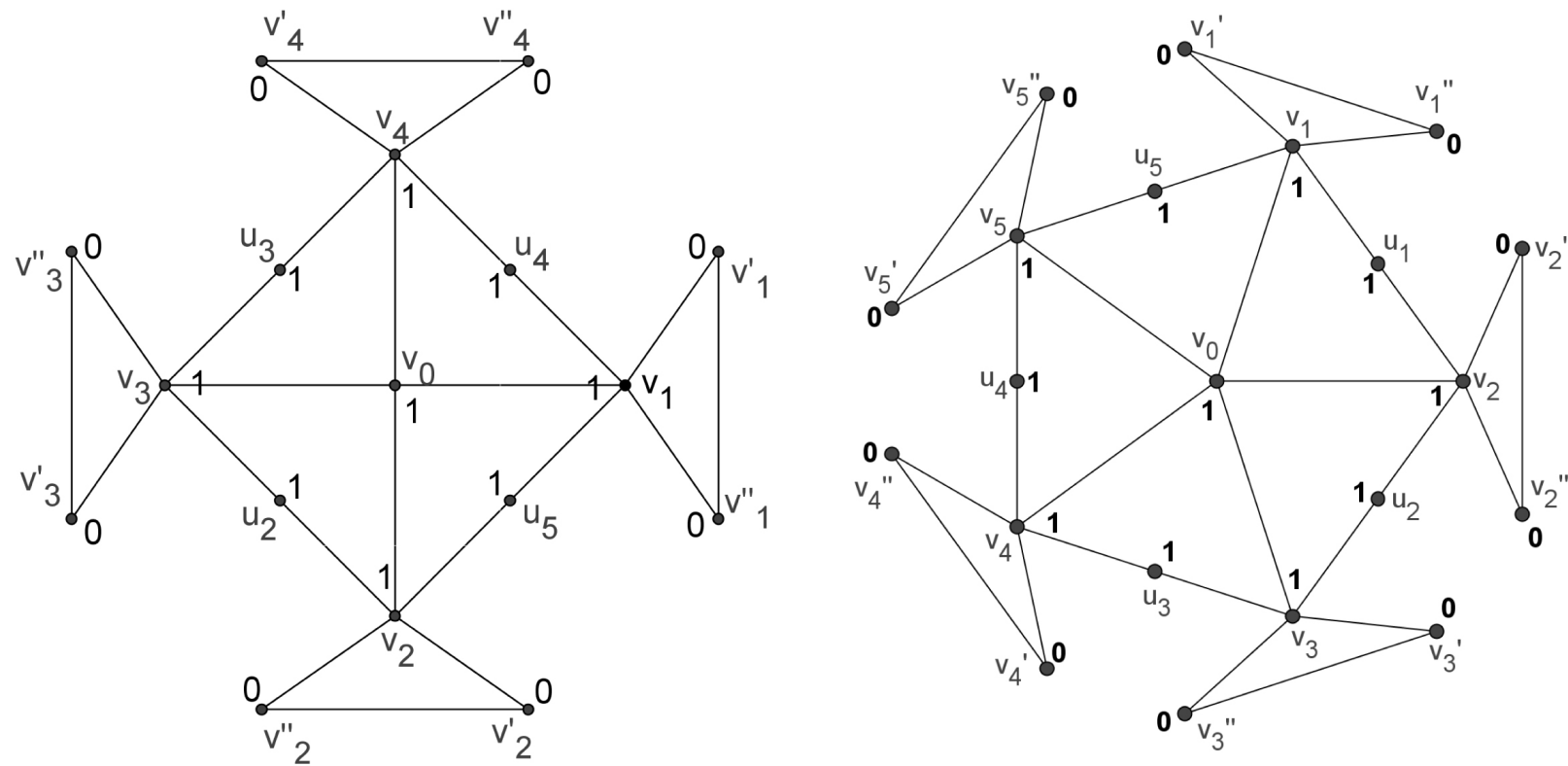

Figure 2. For $n=4$ and $n=5$.

Proof. Let $W_{n}$ be the wheel graph with the apex vertex $v_{0}$ and consecutive rim vertices $v_{1}, v_{2}, v_{3}, \cdots, v_{n}$. To obtain the gear graph $G_{n}$ subdivide each of the rim edges $v_{1} v_{2}, v_{2} v_{3}, \cdots, v_{n-1} v_{n}, v_{n} v_{1}$ of the wheel graph by the vertices $u_{1}, u_{2}, \cdots, u_{n}$ respectively. Obviously $\left|V\left(G_{n}\right)\right|=2 n+1$ and $\left|E\left(G_{n}\right)\right|=3 n$. Let $G$ be the graph obtained from $G_{n}$ by duplicating the apex vertex $v_{0}$ by an edge $v_{0}^{\prime} v_{1}^{\prime \prime}$, clearly $|V(G)|=2 n+3$ and $|E(G)|=3(n+1)$.

Label the first $n+1$ vertices of the sequence $u_{1}, v_{2}, u_{2}, v_{3}, u_{3}, \cdots, u_{n-1}, v_{n}, u_{n}, v_{1}, v_{0}, v_{0}^{\prime}, v_{0}^{\prime \prime}$ each with label 0 and the remaining vertices with label 1 . Thus $v_{f}(0)=n+1$,

$v_{f}(1)=n+2, \quad e_{f}(0)=\frac{3 n+4}{2}$ and $e_{f}(1)=\frac{3 n+2}{2}$. Therfore $\left|v_{f}(0)-v_{f}(1)\right| \leq 1$ and $\left|e_{f}(0)-e_{f}(1)\right| \leq 1$. So it admits product cordial labeling for all even $n$. Hence $G$ is a product cordial graph.

Illustration 3. The product cordial labeling of the graph obtained by duplication of the apex vertex by an edge in gear graph $G_{n}$ for $n=6$ is shown in Figure 3 .

Theorem 5. The graph obtained by switching of a vertex of degree two in gear graph is a product cordial graph.

Proof. Let $W_{n}$ be the wheel graph with the apex vertex $v_{0}$ and consecutive rim vertices $v_{1}, v_{2}, v_{3}, \cdots, v_{n}$. To obtain the gear graph $G_{n}$ subdivide each of the rim edges $v_{1} v_{2}, v_{2} v_{3}, \cdots, v_{n-1} v_{n}, v_{n} v_{1}$ of $W_{n}$ by the vertices $u_{1}, u_{2}, \cdots, u_{n}$ respectively. Obviously $\left|V\left(G_{n}\right)\right|=2 n+1$ and $\left|E\left(G_{n}\right)\right|=3 n$. Let $G$ be the graph obtain by switching the vertex $u_{n}$ in $G_{n}$. Clearly, $|V(G)|=2 n+1$ and $|E(G)|=5 n-4$.

Case 1: $n$ is odd. Label the first $n$ vertices of the sequence $v_{n}, v_{1}, u_{1}, v_{2}, u_{2}, \cdots, v_{n-1}, u_{n-1}, v_{0}, u_{n}$ each with label 0 and the remaining vertices each with label 1. Thus $v_{f}(0)=n, \quad v_{f}(1)=n+1, e_{f}(0)=\left\lceil\frac{5 n-4}{2}\right\rceil$ and $e_{f}(1)=\left\lfloor\frac{5 n-4}{2}\right\rfloor$. 


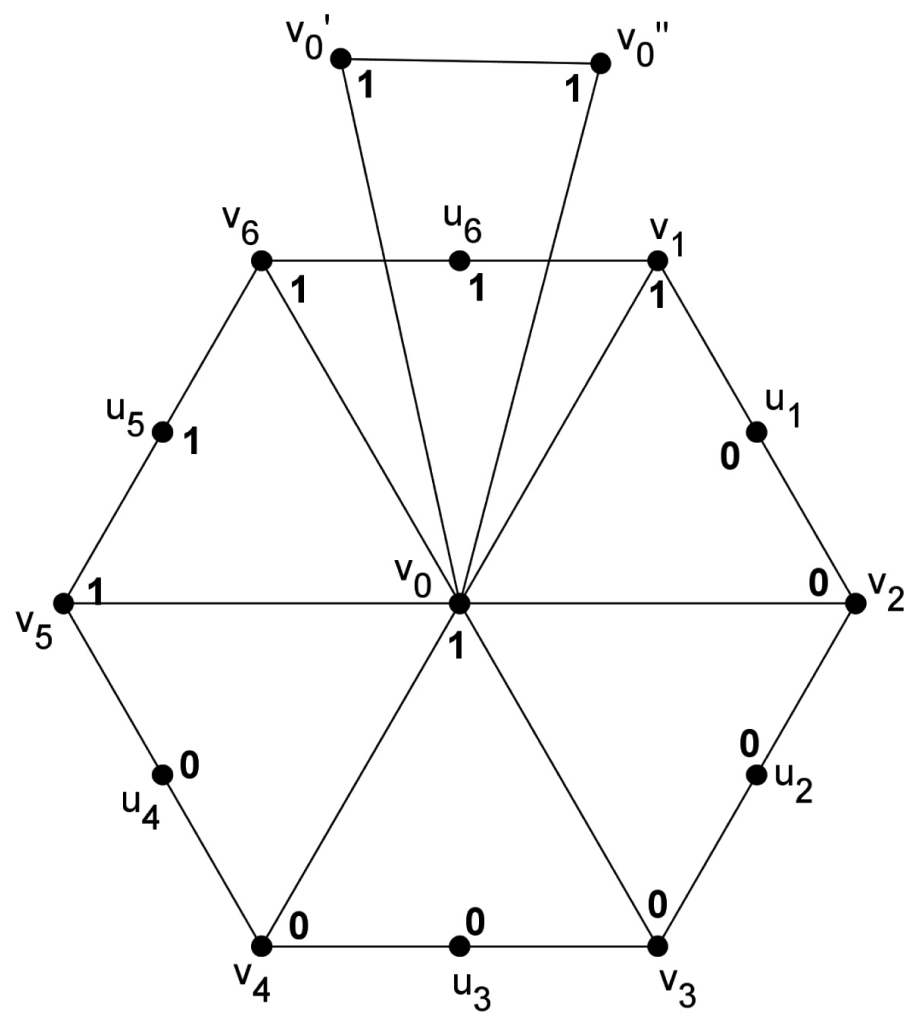

Figure 3. For $n=6$.

Case 2: $n$ is even.

Subcase I: $n \equiv 0(\bmod 4)$

Label first $\frac{n}{2}$ vertices from the sequence $v_{1}, u_{1}, v_{2}, u_{2}, \cdots, v_{\frac{n}{2}-1}, u_{\frac{n}{2}-1}, v_{\frac{n}{2}}$ with label 0 . Also label first $\frac{n}{2}$ vertices from the sequence $v_{n}, u_{n-1}, v_{n-1}, u_{n-2}, \cdots, u_{\frac{n}{2}+1}, v_{\frac{n}{2}+1}, u_{\frac{n}{2}}$ with label 0 and the remaining vertices each with label 1.

Subcase II: $n \equiv 2(\bmod 4)$

Label first $\frac{n}{2}-1$ vertices from the sequence $v_{1}, u_{1}, v_{2}, u_{2}, \cdots, v_{\frac{n}{2}-1}, u_{\frac{n}{2}-1}, v_{\frac{n}{2}}$ with label 0. Also label first $\frac{n}{2}+1$ vertices from the sequence $v_{n}, u_{n-1}, v_{n-1}, u_{n-2}, \cdots, u_{\frac{n}{2}+1}, v_{\frac{n}{2}+1}, u_{\frac{n}{2}}$ with label 0 and the remaining vertices each with label 1.

From both the subcases we get $v_{f}(0)=n, v_{f}(1)=n+1, e_{f}(0)=\frac{5 n-4}{2}$ and $e_{f}(1)=\frac{5 n-4}{2}$

Clearly from both the cases $\left|v_{f}(0)-v_{f}(1)\right| \leq 1$ and $\left|e_{f}(0)-e_{f}(1)\right| \leq 1$. Thus $G$ admits product cordial labeling. Hence $G$ is a product cordial graph.

Illustration 4. The graph obtained by switching of a vertex of degree two in gear graph $G_{n}$ for $n=10$ is shown in Figure 4. 


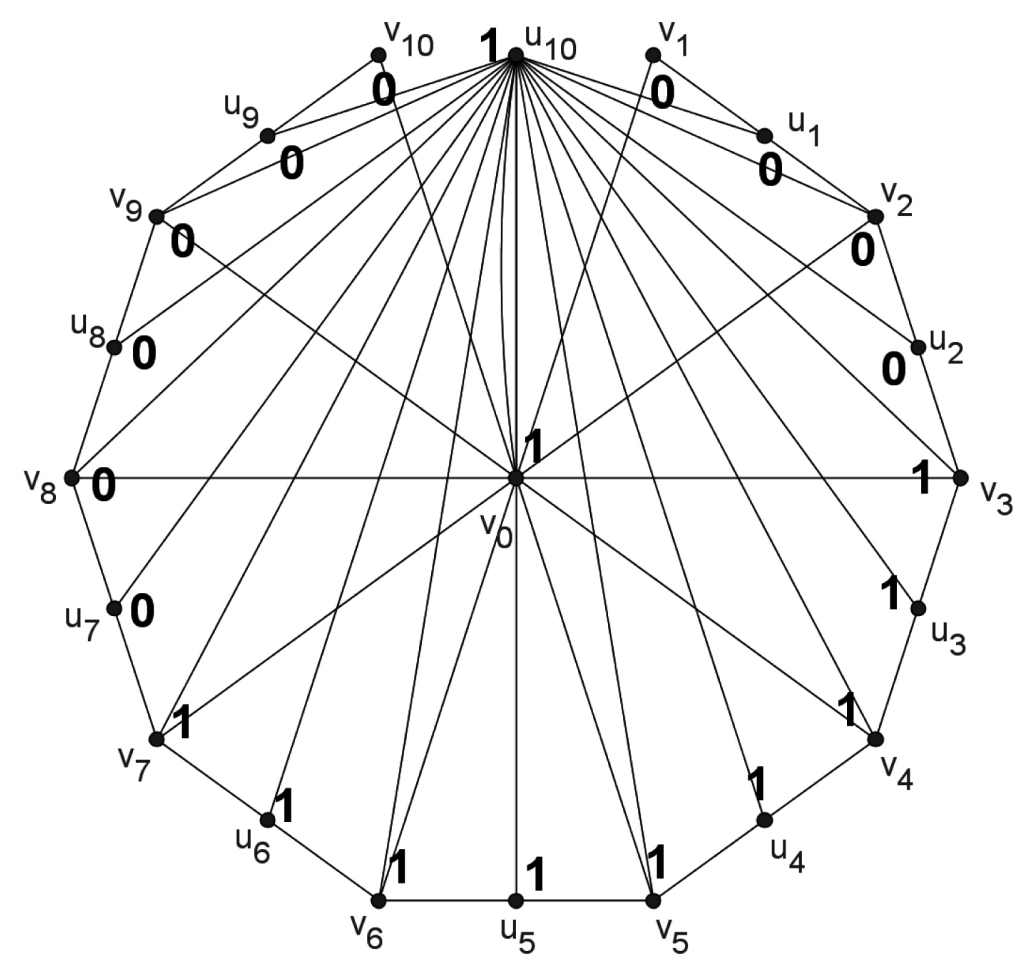

Figure 4. For $n=10$.

Theorem 6. The graph obtained by applying vertex switching on a single vertex of degree three in gear graph is a product cordial graph.

Proof. Let $W_{n}$ be the wheel graph with the apex vertex $v_{0}$ and consecutive rim vertices $v_{1}, v_{2}, v_{3}, \cdots, v_{n}$. To obtain the gear graph $G_{n}$ subdivide each of the rim edges $v_{1} v_{2}, v_{2} v_{3}, \cdots, v_{n-1} v_{n}, v_{n} v_{1}$ of the wheel graph by the vertices $u_{1}, u_{2}, \cdots, u_{n}$ respectively. Obviously $\left|V\left(G_{n}\right)\right|=2 n+1$ and $\left|E\left(G_{n}\right)\right|=3 n$. Let $G_{v_{1}}$ be the graph obtain by applying vertex switching operation on the vertex $v_{1}$. Clearly, $|V(G)|=2 n+1$ and $|E(G)|=5 n-6$.

Case 1: $n$ is odd. Label the first $n$ vertices of the sequence $u_{n}, u_{1}, v_{2}, u_{2}, v_{3}, \cdots, v_{n-1}, u_{n-1}, v_{n}, v_{1}, v_{0}$ each with label 0 and the remaining vertices with label 1. Thus $v_{f}(0)=n, \quad v_{f}(1)=n+1, e_{f}(0)=\left\lceil\frac{5 n-6}{2}\right\rceil$ and $e_{f}(1)=\left\lfloor\frac{5 n-6}{2}\right\rfloor$.

Case 2: $n$ is even. Label the first $n$ vertices of the sequence $u_{n}, u_{1}, v_{2}, u_{2}, v_{3}, \cdots, v_{n-1}, u_{n-1}, v_{n}, v_{1}, v_{0}$ each with label 0 and the remaining vertices with label 1. By this labeling we get $v_{f}(0)=n, v_{f}(1)=n+1, e_{f}(0)=\frac{5 n-6}{2}$ and $e_{f}(1)=\frac{5 n-6}{2}$.

Clearly from both the cases $\left|v_{f}(0)-v_{f}(1)\right| \leq 1$ and $\left|e_{f}(0)-e_{f}(1)\right| \leq 1$. Thus from both the cases $G$ admits product cordial labeling. Hence $G$ is a product cordial graph.

Illustration 5. The graph obtained by switching of a vertex of degree three in gear graph $G_{n}$ for $n=5$ is shown in Figure 5 as follows. 


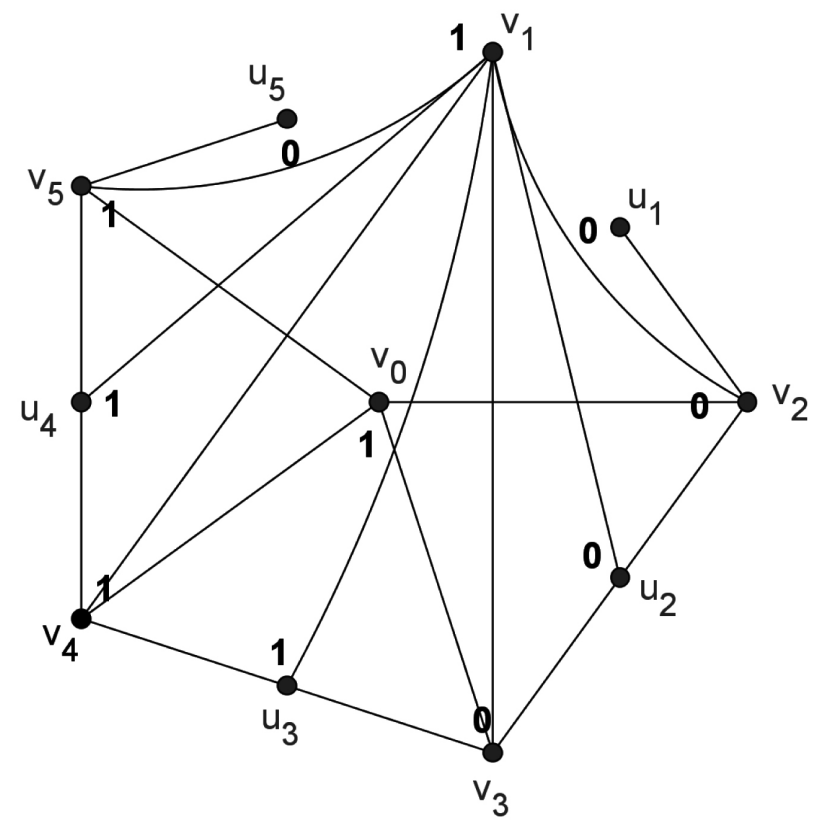

Figure 5. For $n=5$.

Observation 1. The graph obtained by applying vertex switching on the apex vertex in gear graph is a product cordial graph if $n$ is odd and it is not product cordial graph if $n$ is even.

The graph obtained by vertex switching of the apex vertex in the gear graph again yields us a gear graph. Vaidya and Barasara [4] have already proved it in their paper that gear graph is a product cordial graph if $n$ is odd and it is not a product cordial graph if $\mathrm{n}$ is even.

Conjecture 1. The graph obtained by duplication of each vertex of degree three in the gear graph is not a product cordial graph.

Conjecture 2. The graph obtained by duplication of the apex vertex in the gear graph is not a product cordial graph.

Conjecture 3. The graph obtained by switching of a vertex of degree two in gear graph is a product cordial graph.

\section{Conclusion}

We have derived seven results on product cordial labeling of some graphs obtained by duplication of some graph elements in gear graph. Also, we have derived two results on product cordial labeling of some graphs obtained by switching of a vertex of different degrees in the gear graph. Similar problems can be discussed for the graph obtained by duplication of an edge in gear graph. Also, the product cordial labeling can be discussed in the context of these graph operations of wheel graph, helm graph and crown graph.

\section{Acknowledgements}

The first author is thankful to the University Grant Commission, India for supporting 
him with Minor Research Project under No. F. 47-903/14(WRO) dated 11th March, 2015.

\section{References}

[1] Gross, J. and Yellen, J. (2004) Handbook of Graph Theory. CRC Press, Boca Raton.

[2] Gallian, J.A. (2014) A Dynamic Survey of Graph Labeling. The Electronic Journal of Combinatorics, 17, \#DS6.

[3] Sundaram, M., Ponraj, R. and Somasundaram, S. (2004) Product Cordial Labeling of Graphs. Bulletin of Pure \& Applied Sciences-Mathematics \& Statistics, 23E, 155-163.

[4] Vaidya, S.K. and Barasara, C.M. (2012) Further Results on Product Cordial Labeling. International Journal of Mathematical Combinatorics, No. 3, 64-71.

[5] Vaidya, S.K. and Barasara, C.M. (2011) Product Cordial Graphs in the Context of Some Graph Operations. International Journal of Computing Science and Mathematics, 1, 1-6.

[6] Vaidya, S.K., Srivastav, S., Kaneria, V.J. and Kanani, K.K. (2010) Some Cycle Related Cordial Graphs in the Context of Vertex Switching. Proceedings of International Conference on Discrete Mathematics, 2008 RMS Lecturer Note Series, No. 13, 243-252.

Submit or recommend next manuscript to SCIRP and we will provide best service for you:

Accepting pre-submission inquiries through Email, Facebook, LinkedIn, Twitter, etc. A wide selection of journals (inclusive of 9 subjects, more than 200 journals)

Providing 24-hour high-quality service

User-friendly online submission system

Fair and swift peer-review system

Efficient typesetting and proofreading procedure

Display of the result of downloads and visits, as well as the number of cited articles Maximum dissemination of your research work

Submit your manuscript at: http://papersubmission.scirp.org/ 